\title{
A normalized statistical study of Earth's cusp region based on nine-years of Cluster measurements
}

\author{
Chao Xiao ${ }^{1,2}$, WenLong Liu 1,2*, DianJun Zhang ${ }^{1,2}$, and Zhao Zhang ${ }^{1,2}$ \\ ${ }^{1}$ School of Space and Environment, Beihang University, Beijing 102206, China; \\ ${ }^{2}$ Key Laboratory of Space Environment monitoring and Information Processing of MIIT, Beijing 102206, China \\ Key Points: \\ - The relationship between $X$ and $Z$ is linear for the center of the cusp \\ - The relationship is quadratic between cusp width in the direction and $Z$ \\ - A new normalized statistical method is developed for cusp investigations
}

Citation: Xiao, C., Liu, W. L., Zhang, D. J., and Zhang, Z. (2020). A normalized statistical study of Earth's cusp region based on nine-years of Cluster measurements. Earth Planet. Phys., 4(3), 266-273. http://doi.org/10.26464/epp2020031

\begin{abstract}
Nine years (2001-2009) of data from the Cluster spacecraft are analyzed in this study of the Earth's mid-and high-altitude $\left(2-9 R_{\mathrm{E}}\right)$ cusp. Properties of the cusp region, and its location and size in the Solar Magnetic coordinate system, are studied statistically. The survey shows that (1) the relationships between $X$ and $Z$ are nearly linear for the poleward, equatorward boundaries and the center of the cusp; (2) the relationship between cusp width in the $X$ direction and $Z$ can be expressed by a quadratic function; (3) the cusp region is almost dawn-dusk symmetric for the cusp width in the $X$ direction. Based on topology information, a new normalized statistical methodology is developed to organize the measurements of cusp crossings to obtain distributions of magnetic field and plasma parameters in the $X Z$ plane. The statistical results show that (1) $B_{X}$ is mostly negative and $B_{z}$ is always negative; (2) proton velocity is found to be positive for $V_{x}$ and $V_{z}$ at low altitudes, while $V_{x}$ and $V_{z}$ are negative on the equator side and negative $V_{x}$ and positive $V_{z}$ on the pole side at high altitudes; (3) proton density is higher on the equator side than on the pole side. Results reported here will be useful in suggesting directions for future cusp research.
\end{abstract}

Keywords: cusp; statistical study; new methodology; topology

\section{Introduction}

Chapman and Ferraro (1930) first discussed the Earth's magnetospheric cusp, through which the solar wind plasma can directly enter the magnetosphere and the ionosphere without crossing geomagnetic field lines. Heikkila (1985) described vividly the shape of the magnetospheric cusp region as a narrow funnel. The magnetospheric cusp is a key region for studies of flux transfer events (Russell and Elphic, 1979), the signatures of magnetic reconnection at the magnetopause (e.g., Dungey, 1961; Lockwood and Smith, 1994; Cao D et al., 2017; Peng FZ et al., 2017), and heavy ion outflow from ionosphere (Yu YQ and Ridley, 2013). Heikkila and Winningham (1971) used observations of ISIS 1 spacecraft to observe the polar cusps for the first time. The plasma mantle (Rosenbauer et al., 1975) and the entry layer (Paschmann et al., 1976) are, respectively, the poleward and equatorward regions of the cusp. The plasma mantle, a loss channel for the plasma of the cusp, is formed by reconnected field lines (e.g., Sckopke et al., 1976; Sckopke and Paschmann, 1978): the entry layer

Correspondence to: W. L. Liu, liuwenlong@buaa.edu.cn

Received 05 FEB 2020; Accepted 31 MAR 2020.

Accepted article online 08 MAY 2020.

(C) 2020 by Earth and Planetary Physics. is an important structure at which magnetosheath plasma can enter the closed magnetic field lines through diffusion processes (e.g., Haerendel and Paschmann, 1982), turbulence (e.g., Haerendel et al., 1978), and magnetic reconnection (e.g., Zong Q-G et al., 2005; Shi QQ et al., 2009a).

Because of the importance of the magnetospheric cusp, many studies have been extensively carried out, for example, on the interaction between the cusp region and interplanetary magnetic fields (IMF) (e.g., Chen JA and Fritz, 1998; Savin et al., 1998, 2002, 2004; Le et al., 2001; Nykyri et al., 2004, 2006, 2011; Zhang H et al., 2005; Shi QQ et al., 2009a; Liu WL et al., 2016; Xiao C et al., 2018), on the topology of the cusp (e.g., Zong Q-G et al., 2004, 2006; Cao JB et al., 2005; Dunlop et al., 2005; Zhang H et al., 2006, 2007; Shi QQ et al., 2009b; Shen C et al., 2011), on dynamic processes of the cusp (e.g., Chen JS et al., 2005; Duan SP et al., 2006; Yu YQ and Ridley, 2009; Wang TY et al., 2014) and on the trajectories of particles in the cusp region and their connections with the IMF and the equatorial magnetosphere (e.g., Sheldon et al., 1998; Delcourt and Sauvaud, 1999; Zhou XZ et al., 2006). Several studies have used data from different instrumentations aboard different spacecraft to determine the location, size, and properties of the magnetospheric cusp at different altitudes (e.g., Newell and Meng, 1989; Lockwood and Smith, 1992; Russell et al., 1998; Savin et al., 1998; 
Lavraud et al., 2002). For the location of the cusp, the dipole tilt has an important impact on the magnetic latitude of the cusp (e.g., Newell and Meng, 1989; Zhou XW et al., 1999; Palmroth et al., 2001) and the magnetic latitude of the cusp becomes more sensitive to dipole tilt as the altitude increases (Měrka et al., 2002). The magnetic latitude of the cusp is related to the southward IMF $B_{z}$ (Newell and Meng, 1987; Escoubet and Bosqued, 1989; Newell et al., 1989; Zhou XW et al., 2000; Palmroth et al., 2001; Pitout et al., 2006; Prölss, 2006; Niehof et al., 2010; Johnsen and Lorentzen, 2012). Previous studies have also showed that the size of the cusp is determined primarily by altitude, ranging from a few hundred kilometers at $\sim 835 \mathrm{~km}$ (Newell and Meng, 1994) to several Earth radii at $\sim 8 R_{\mathrm{E}}$ (Chen JS et al., 2005). The solar wind is considered to be another important factor affecting the size of the cusp (Zhou XW et al., 2000; Pitout et al., 2006). For plasma and magnetic properties of the cusp, some statistical studies have been carried out, using data from Cluster. For example, Lavraud et al. (2004, 2005), using a sampling method first introduced by Grigoriev et al. (1999), have studied statistically the spatial distributions of the magnetic field and plasma parameters in the high-latitude cusp region. Walsh and Fritz (2011) used the same method to perform a seven-year statistical study of the energetic electron population in the high-altitude cusp and presented energetic electron populations consistent with local acceleration.

From the previously mentioned studies, we have learned that the cusp is a highly disturbed region in terms of position and size, varying with solar wind and IMF conditions, which leads to difficulty in the statistics studies when the determination of cusp boundary is necessary. Use of long-term observations from the Cluster mission allows us to propose a new normalized method for statistical description of cusp properties. We first study the topology of the cusp at mid- and high-altitudes (from $\sim 2 R_{\mathrm{E}}$ to $\sim 9 R_{\mathrm{E}}$ ), and, by organizing observations in a normalized grids of cusp region, subsequently use these findings to develop a new methodology for study of the statistical distributions of magnetic field and plasma parameters. The remainder of this paper is organized as follows. Section 2 describes typical cusp crossings and provides criteria for determining the cusp region. Section 3 presents statistical results on the location, size, and (the plasma and magnetic) properties of the cusp. Section 4 is devoted to discussion and conclusions.

\section{Example of a Cusp Crossing Event}

A typical cusp crossing event observed by Cluster on 8 Sep 2002 is shown in this section, helping us to understand the signatures of a cusp crossing. Figures $1 \mathrm{a}$ and $1 \mathrm{~b}$ illustrate the Cluster-3 (C3Samba) spacecraft position in Geocentric Solar Magnetospheric (GSM) coordinates; the GSM $X$-axis is from the Earth to the Sun; its positive $Z$-axis is chosen to be in the same sense as the Earth's northern magnetic pole; its $Y$-axis is defined to be perpendicular to the Earth's magnetic dipole, so that the $X Z$ plane contains the dipole axis. We use the magnetic field lines calculated by the Tsyganenko and Stern (1996) model. The satellite moves from dayside to nightside magnetosphere with a possible cusp crossing. Overview of magnetic field and plasma parameters recorded by C3 from 05:00 UT to 07:00 UT are shown in Figures 1c-1g. From the three components of the magnetic field shown in Figure $1 c$, in GSM coordinates, there is no obvious magnetic field change associated with cusp crossing in this event. However, the cusp region can be distinguished clearly in ion measurements from the Hot Ion Analyzer (HIA) of the Cluster lon Spectrometry (CIS) instrument (Rème et al., 2001), as shown, respectively, in Figure 1d for the spectra of ion omni-directional energy fluxes, in Figure 1e for ion density, in Figure if for ion bulk flow velocity in GSM coordinates, and in Figure $1 \mathrm{~g}$ for ion temperature. From Figure 1 we can distinguish that, before 06:05 UT, the spacecraft was in the dayside magnetosphere, which is characterized by strong magnetic field, low ion density and velocity, and high ion temperature. At about 06:05 UT, the satellite entered into the cusp region: the ion energy spectrogram shows a broadband signature, ion number density is increasing rapidly from $\sim 0.4 \mathrm{~cm}^{-3}$ to $\sim 20 \mathrm{~cm}^{-3}$, and ion temperature is decreasing from $30-35$ MK to 3-10 MK. The Cluster satellite remained in the cusp region until it entered the dayside magnetosphere at around 06:36 UT: the ion density begins to fall from $\sim 20 \mathrm{~cm}^{-3}$ to the low densities $\left(\sim 0.2 \mathrm{~cm}^{-3}\right)$ and the ion energy spectrogram becomes a narrowband signature, the ion temperature descending to 1-3 MK. The signatures of the cusp region recorded in the ion energy spectrogram, ion number density, and ion temperature, as revealed in this event, can be used to identify a cusp crossing and to study the characteristic of the cusp region, as discussed below in the following sections.

\section{Statistical Study}

In this study, we analyze Cluster data collected from 2001 to 2009 in the region of $-1<X<10 R_{\mathrm{E}}$ and $|Y|<8 R_{\mathrm{E}}$ in the Solar Magnetic coordinate system (SM): the positive SM Z-axis is chosen parallel to the Earth's north magnetic pole; its $Y$-axis is perpendicular to the Earth-Sun line towards dusk. We manually selected 470 cusp crossing events observed from the Cluster- 3 spacecraft in the northern hemisphere, based on the crossing signatures described in the previous section. Histograms of the distribution of the number of events are plotted for year and month in Figures $2 a$ and $2 b$, respectively. Due to the precession of the Cluster trajectory, most of the crossings were observed in the spring and fall seasons.

\subsection{Statistical Study of Cusp Boundaries}

The locations of the two cusp boundaries are investigated statistically for poleward boundary ( $\mathrm{PoB})$ and equatorward boundary (EqB). The SM coordinate system is used to eliminate the impact of dipole tilt angle on cusp boundary locations (Newell and Meng, 1989; Zhou XW et al., 1999; Palmroth et al., 2001; Mĕrka et al., 2002). Figures $2 c-2 e$ show projections of the positions of the two boundaries: onto the $X Z$ plane (Figure $2 \mathrm{c}$ ), onto the $Y Z$ plane (Figure $2 \mathrm{~d}$ ), and onto the $X Y$ plane (Figure 2e); the red/blue dots represent $\mathrm{PoB} / \mathrm{EqB}$, respectively. Empirical relations between $X$ and $Z$ are fitted from the observations as $X=0.525 Z-1.129(c c \approx 0.72)$ for $\mathrm{PoB}$ and $X=0.88 Z-1.408$ ( $c c \approx 0.87$ ) for EqB, as shown, respectively, by the red and blue lines in Figure 2c. Subsequently, the center of the cusp in the $X Z$ plane can be described as $X=$ $0.731 Z-1.43$ (cc $\approx 0.84$ ), as shown by the black line in Figure $2 c$. It should be noted that PoB or EqB is controlled by solar wind (Zhou XW et al., 2000; Pitout et al., 2006) and IMF conditions (Escoubet 

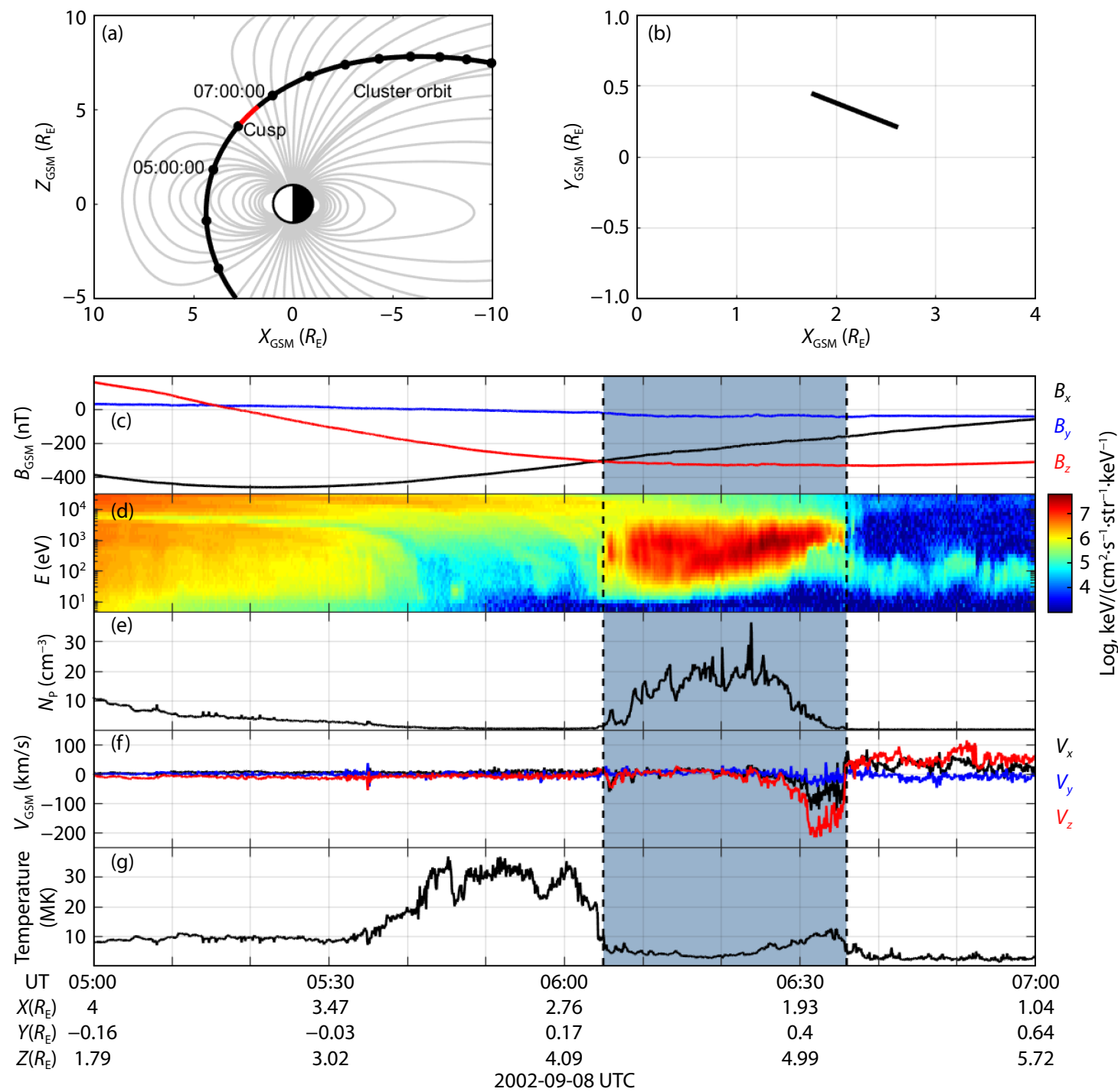

Figure 1. A northern cusp crossing occurred on 8 Sep 2002. Panel (a): the orbit of Cluster C3 is projected into the GSM XZ plane, where the dots are hour markings; the cusp region is marked by red; the background field lines are computed using the T96 magnetic field model (Tsyganenko and Stern, 1996). Panel (b) presents the orbit of Cluster C3 in the GSM XY plane through the cusp region. Panel (c) shows the FGM magnetic field measurements. Panels (d), (e), (f), and (g) show the ion energy spectrogram, number density, velocity, and temperature from C3, respectively.

and Bosqued, 1989; Newell et al., 1989; Zhou XW et al., 2000; Palmroth et al., 2001; Pitout et al., 2006; Niehof et al., 2010; Johnsen and Lorentzen, 2012); however in this paper we calculate only the average locations of the two boundaries while leaving their solar wind and IMF dependence for future study. Figures $2 \mathrm{~d}-2 \mathrm{e}$ show that the scale of the cusp in the $Y$ direction increases nearly linearly with increasing $X(Z)$, making the cusp region look intuitively like a funnel. Figures $2 f$ and $2 g$ display the corresponding MLT (Magnetic Local Time) distribution of PoB and EqB, respectively, showing that both boundaries are located mainly between 08:00 and 16:00 MLT.

The widths of all individual cusp crossings are investigated. Previous studies have shown that the width of the cusp increases with increasing $X$ and $Z$, resulting in a funnel-like shape: the width of the cusp may be only a few hundred kilometers in the ionosphere (Newell and Meng, 1994) and increases to several Earth radii at high-altitudes (Chen JS et al., 2005). In this study, we define the width in the $X$ direction $\left(W_{x}\right)$ as $\left|P_{\mathrm{PoB}} P_{\mathrm{EqB}}\right|=\left|x_{2}-x_{1}\right|$, where $P_{\mathrm{PoB}}=\left(x_{1}, y_{1}, z_{1}\right)$ and $P_{\mathrm{EqB}}=\left(x_{2}, y_{2}, z_{2}\right)$.

Scatter plots of cusp widths are shown in Figure 3 for the 470 cusp crossing events. Figure $3 a$ shows the scatter plot of $W_{x}$ as a function of $Z$. It is clear that $W_{x}$ increases with increasing $Z$. This relationship can be fitted by a quadratic function as $W_{x}=0.43-0.17 Z+$ $0.064 Z^{2}$, with correlation coefficient of $c c 1=0.729$ calculated for the data points and $c c 2=0.992$ for bin averaged values. The scatter plot of $W_{x}$ and $R$ (the radial distance to the center of the Earth) is shown in Figure $3 d$, in which a similar relationship can be observed.

Next we study $W_{x}$ along the dawn-dusk direction. Figure $3 c$ shows $W_{x}$ as a function of $Y$ for the events with geocentric distance $(R)$ between 4 and $6 R_{\mathrm{E}}$. It can be seen that $W_{x}$ decreases with increasing $|Y|$ and is almost dawn-dusk symmetric. Similar conclusions can be drawn from the relationship between the cusp $W_{x}$ and 

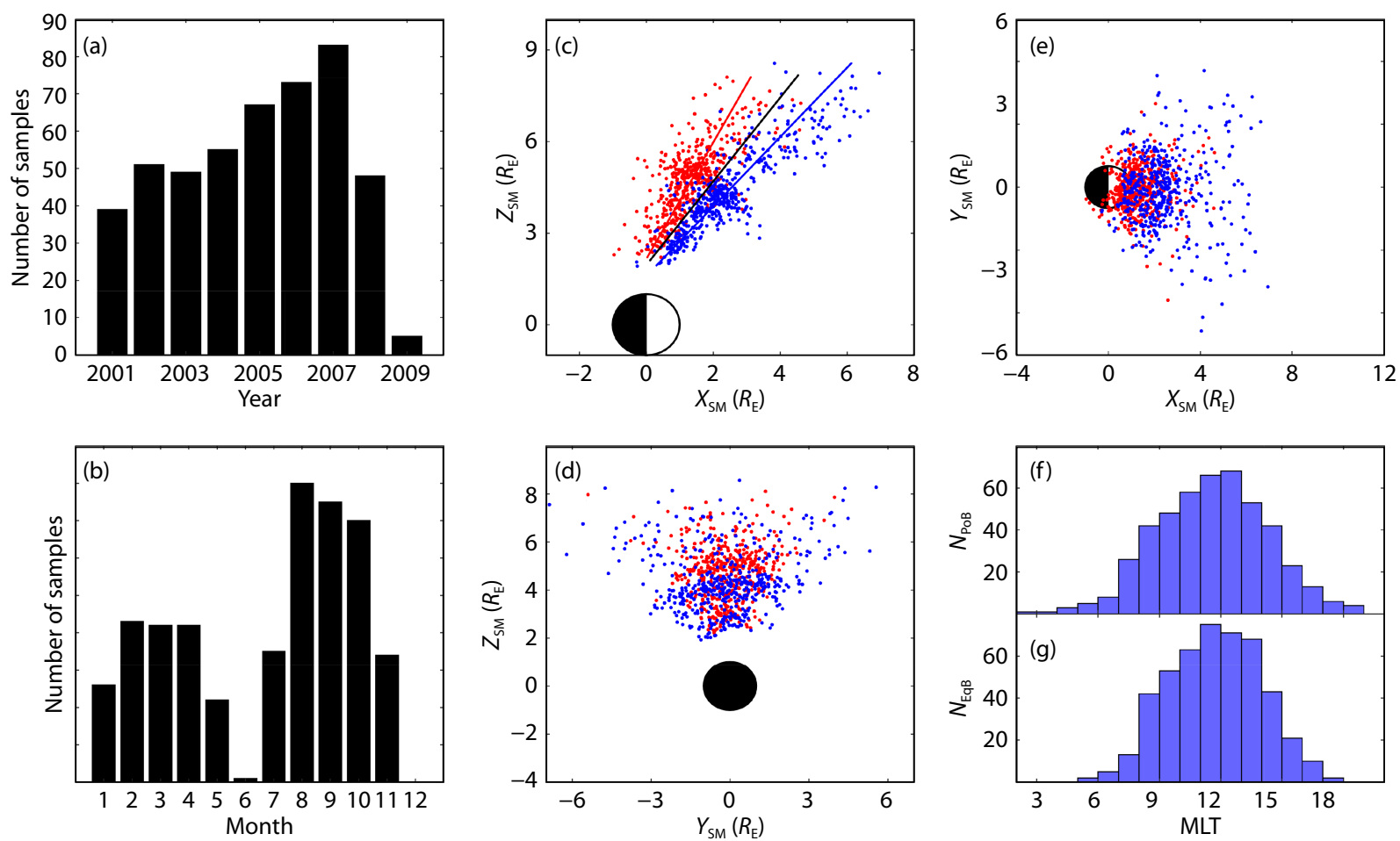

Figure 2. Histogram of (a) year and (b) month of cusp crossing events. The observed locations of northward cusp's boundaries are projected onto (c) the $X Z$ plane, (d) the $Y Z$ plane, and (e) the $X Y$ plane. Blue and red dots designate EqB and PoB, respectively. Histogram of the corresponding MLT distributions of $(f)$ PoB and (g) EqB.

MLT, as shown in Figure 3d. It is also clear from this scatter plot that $W_{x}$ decreases with increasing $|M L T-12|$ value and is dawndusk symmetric.

\subsection{Statistical Study of Plasma Properties}

Based on topology information obtained in previous sections, spatial distributions of the cusp's physical parameters are studied, again using data from these cusp crossing events. The spacecraft position during a cusp crossing is normalized as 0 to 1 from $P o B$ to EqB in $X$ direction, dividing the cusp region into 21 by 21 grids ( $X$ : from 0 to $1 ; Z$ : from 2 to $8 R_{\mathrm{E}}$ ). Magnetic field and plasma measurements for cusp crossings are subsequently averaged in each grid with the identified cusp crossing events to obtain the global statistical properties of the cusp.

Figure 4a shows the number of observations in the normalized grids. From the previous section, the cusp width in the $X$ direction is given by $W_{x}=0.43-0.17 Z+0.064 Z^{2}$ and the $X$ axis is given by $X$ $=0.731 Z-1.43$; thus the normalized grid can be converted to the $X Y$ plane in the SM coordinate system, as shown in Figure 4b. Consistent with previous studies (Heikkila, 1985), the cusp region appears to be funnel-shaped. The background magnetic field lines (the dashed lines) in Figure 4b are computed by the T96 magnetic field model (Tsyganenko and Stern, 1996).

By using this new methodology, the spatial distribution of the physical parameters of the cusp are obtained in SM coordinates (Figure 5). Figures $5 \mathrm{a}$ and $5 \mathrm{~b}$ show the spatial distribution of the $X$ and $Z$ components of the magnetic field $B_{x}$ and $B_{z}$, respectively. It is obvious that the amplitude of $B_{X}$ (variation range: -1500 to 1000 $\mathrm{nT}$ ) and $B_{z}$ (variation range: -3700 to $0 \mathrm{nT}$ ) gradually increase with decreasing altitude. Figure $5 c$ shows that the magnetic field vectors in the $X Z$ plane are very consistent with values predicted by the T96 model. Combining Figures 5a, 5b, and 5c, we find that the $B_{x}$ is mostly negative and the $B_{z}$ is always negative. This result implies that the cusp region is bent primarily to the equator side in the SM coordinate system. Because $B_{z}$ is dominant in the cusp region, as shown in Figure $5 \mathrm{~b}$, the magnetic field amplitude on the pole side is larger than that on the equator side at the same altitude.

Similarly, Figures $5 e, 5 f$ and $5 g$, respectively, present the spatial distributions of the $X$ and $Z$ components of the proton velocity $\left(V_{x}\right.$ and $V_{Z}$ ) and the proton velocity vectors in the $X Z$ plane. The statistical results show that $V_{x}$ (variation range: -30 to $30 \mathrm{~km} / \mathrm{s}$ ) is positive on the pole (equator) side below about $6 R_{\mathrm{E}}\left(5 R_{\mathrm{E}}\right)$ and turns negative over this altitude. $V_{z}$ (variation range: -25 to $60 \mathrm{~km} / \mathrm{s}$ ) is positive in most areas of the cusp region except at high altitudes (greater than $6 R_{\mathrm{E}}$ ) and on the equator side. For proton velocity (positive $V_{x}$ and $V_{z}$ ) at low altitudes, the cause may be upstream particle flow and the tilt of the cusp region. For proton velocity (negative $V_{x}$ and $V_{z}$ on the equator side, negative $V_{x}$ and positive $V_{z}$ on the pole side) at high altitudes, the cause may be dragging of the solar wind, the magnetic reconnection at the sub-solar magnetopause (e.g., Cargill et al., 2005; Lavraud et al., 2005) and the tilt of the cusp region. Figure $5 \mathrm{~d}$ shows that the spatial distribution of the proton density (variation range: $0-9 \mathrm{~cm}^{-3}$ ) is higher on the equator side than on the pole side, and this may be caused by a higher magnetic pressure on the pole side. The proton temperature (0-12 MK), which is very high at EqB as shown in Figure $5 \mathrm{~h}$, may be caused by the high dynamic pressure near the day- 

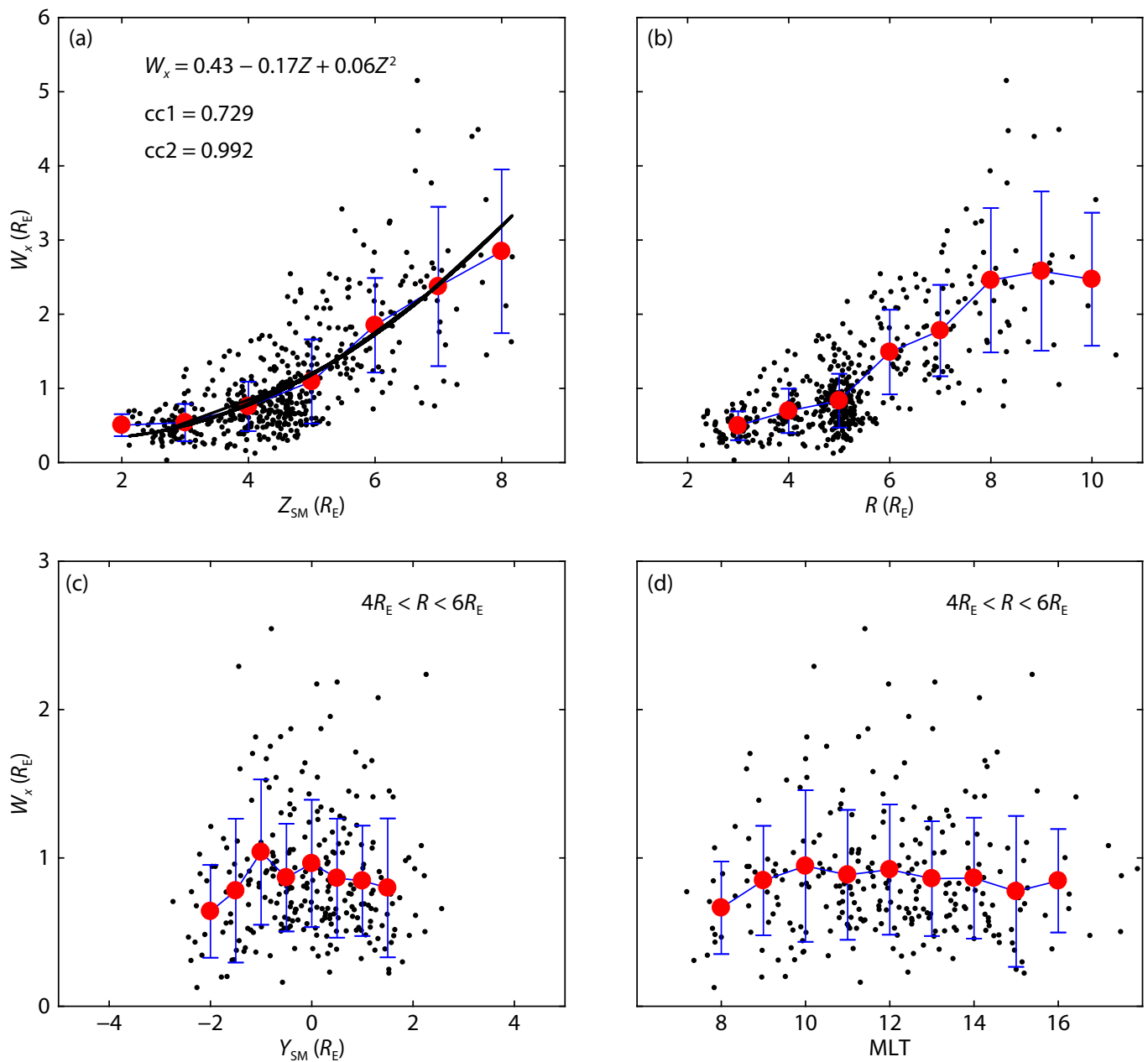

Figure 3. The relationship between $W_{x}$ and (a) $Z$, (b) $R,(\mathrm{c}) Y$, and (d) MLT. In panels (c) and (d), the condition of data selection is that $R$ is greater than $4 R_{\mathrm{E}}$ and less than $6 R_{\mathrm{E}}$. Except that the bin size is $0.5 R_{\mathrm{E}}$ in panel (c), the bin size is $1 R_{\mathrm{E}}$ or hour in the other panels and the error-bars indicate the standard deviation of the binned average widths. The SM coordinates are used in all panels here.

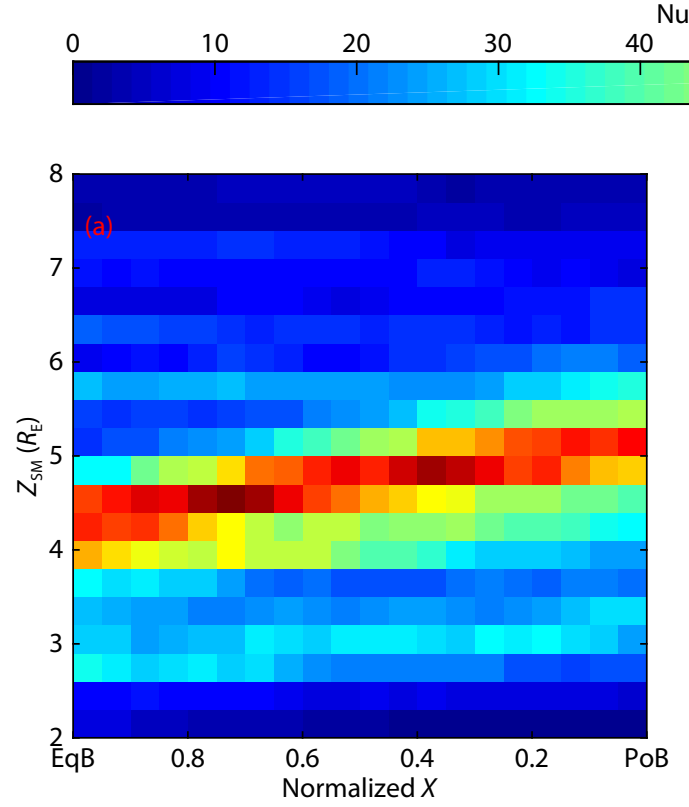

Number

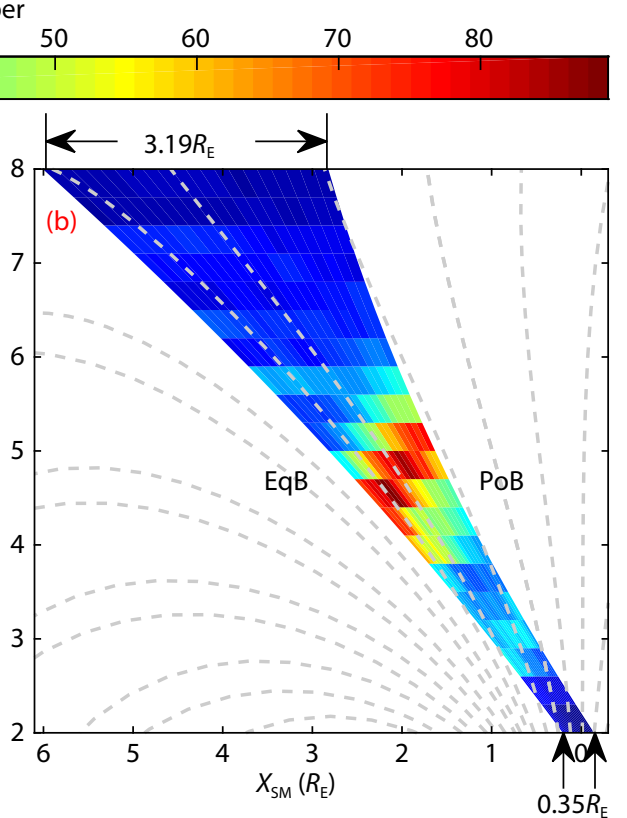

Figure 4. The observation number in the $X Z$ plane: (a) normalized $X,(b)$ normal $X$. The dashed lines in plane (b) are the background magnetic field lines, which are computed by the T96 magnetic field model (Tsyganenko and Stern, 1996). 

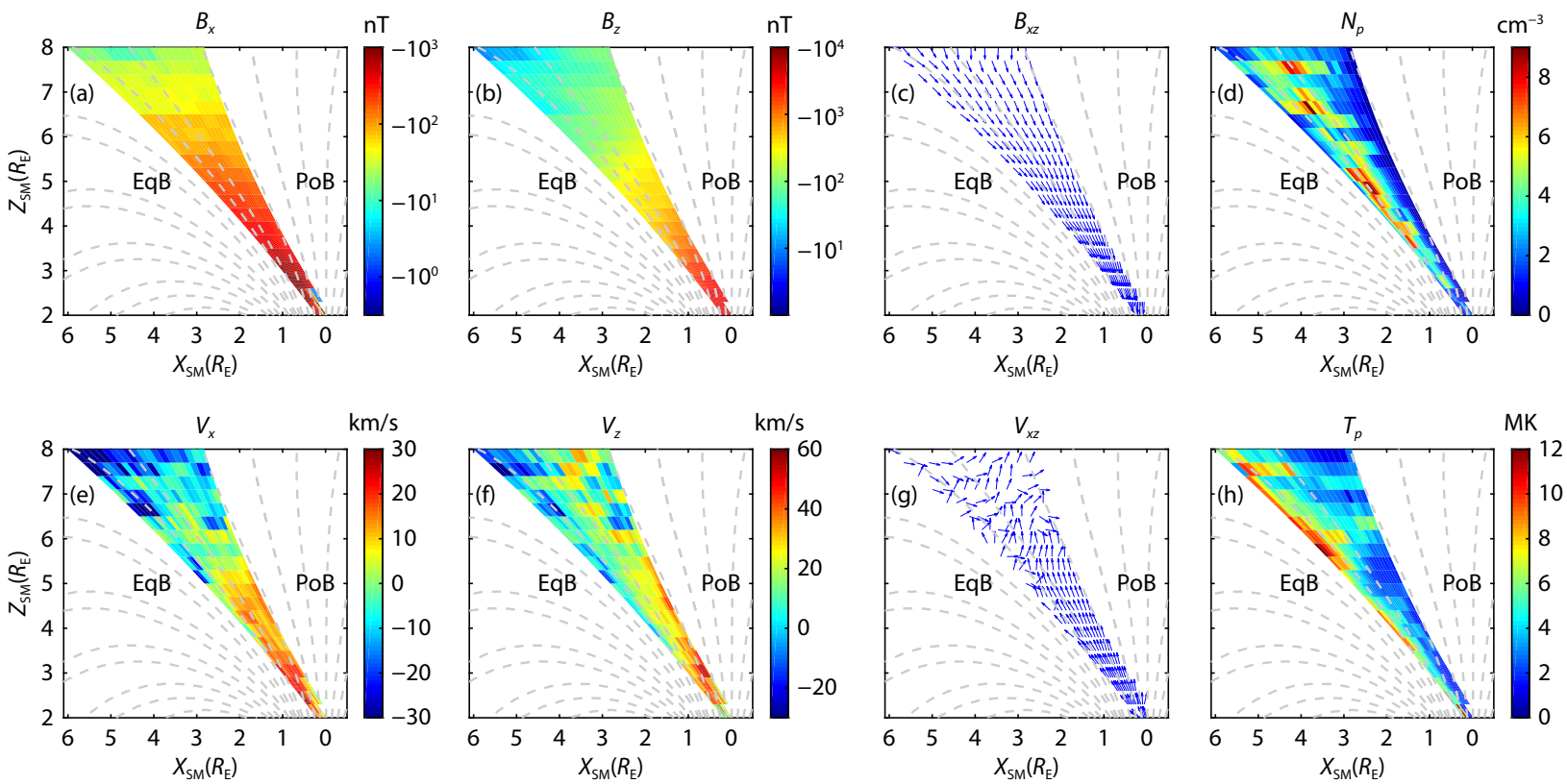

Figure 5. The spatial distribution of (a) the $X$ component of the magnetic field, (b) the $Z$ component of the magnetic field, (c) the magnetic field vectors, (d) the proton density, (e) the $X$ component of the proton velocity, (f) the $Z$ component of the proton velocity, ( $g$ ) the proton velocity vectors, and $(h)$ the proton temperature.

side magnetosphere.

\section{Summary and Discussion}

In this paper, we have investigated the position, size, and global characteristics of the mid- and high-altitude cusp using data from a nine year (2001-2009) statistical survey by the Cluster spacecraft that includes a total of 470 crossing events. A new orbitsampling methodology has been introduced for studying the global characteristics of the cusp region.

Previous studies (e.g., Newell and Meng, 1989; Zhou XW et al., 1999; Palmroth et al., 2001) have revealed that the dipole tilt angle has a great impact on the locations of the cusp boundaries. In order to eliminate this impact, the SM coordinate system has been used in this paper. The EqB and $\mathrm{PoB}$ for the altitudes from 2 to $9 R_{\mathrm{E}}$ are identified from Cluster measurements. In the $S M$ coordinate system, there is a clear separation between $\mathrm{PoB}$ and EqB, and the relations between $X$ and $Z$ are nearly linear for the poleward, equatorward boundaries and the center of the cusp. Especially, the relation for the center of the cusp can be described as $X=$ $0.731 Z-1.43$ ( $c c \approx 0.84$ ). We found that the scale of the cusp region in the $Y$ direction increases nearly linearly with increasing $X$ or $Z$, and that both of the boundaries are located primarily between 08:00 and 16:00 MLT.

Subsequently we studied $W_{x}$. We found that (1) the relationship between $W_{x}$ and $Z$ is consistent with previous studies and can be expressed by $W_{x}=0.43-0.17 Z+0.064 Z^{2}$; (2) the relationship between $W_{x}$ and $Y(\mathrm{MLT})$ suggests that the cusp region is nearly dawn-dusk symmetric.

A number of statistical studies of the cusp region have been previously presented (Zhou XW et al., 1999, 2000; Lavraud et al., 2004, 2005; Walsh and Fritz, 2011). However, except that Lavraud et al.
(2004, 2005) and Walsh and Fritz (2011) used an elaborate orbitsampling methodology which uses the Tsyganenko and Stern (1996) magnetic field model and takes into account the geomagnetic activity and actual solar wind conditions, and most of these studies have ordered crossing data spatially by using simple coordinates systems (such as SM, GSE ans GSM). In this paper, to study the spatial distributions of the cusp's global properties we have employed a new orbit-sampling methodology that uses normalized coordinates to eliminate distortions of cusp topology. The statistical results of this method can be displayed intuitively. We report a spatial distribution of the magnetic field in which $B_{x}$ is mostly negative, $B_{z}$ is always negative, and the magnetic field vectors in the $X Z$ plane are consistent with T96 model calculations. At low altitudes, the proton velocity is found to be positive for $V_{x}$ and $V_{z}$, while at high altitudes, we report negative $V_{x}$ and $V_{z}$ on the equator side and negative $V_{x}$ and positive $V_{z}$ on the pole side. The proton density is higher on the equator side than on the pole side. The high dynamic pressure near the dayside magnetosphere may lead to the very high proton temperature at EqB. The methodology and statistical results shown in this paper suggest directions for future cusp studies.

\section{Acknowledgments}

This work was supported by the National Natural Science Foundation of China, grants 41821003, 41974194 and 41574154 . The authors are thankful to the Cluster team and the Cluster Science Archive for providing Cluster data, which are available at https://csa.esac.esa.int/csa-web/\#home. We also acknowledge use of the OMNIWeb service of NASA/GSFC's Space Physics Data Facility. The OMNI data are available at http://cdaweb.gsfc.nasa.gov/. 


\section{References}

Cao, D., Fu, H. S., Cao, J. B., Wang, T. Y., Graham, D. B., Chen, Z. Z., Peng, F. Z., Huang, S. Y., Khotyaintsev, Y. V., ... Burch, J. L. (2017). MMS observations of whistler waves in electron diffusion region. Geophys. Res. Lett., 44(9), 3954-3962. https://doi.org/10.1002/2017GL072703

Cao, J. B., Leonovich, A., Zhou, G. C., Liu, Z. X., Reme, H., Dandouras, I. (2005). A theoretic interpretation of movement of the cusp equatorward boundary. Chinese Journal of Space Science, 25(5), 412-417. https://doi.org/10.11728/cjss2005.05.412

Cargill, P. J., Lavraud, B., Owen, C. J., Grison, B., Dunlop, M. W., CornilleauWehrlin, N., Escoubet, C. P., Paschmann, G., Phan, T. D., ... Nykyri, K. (2005). Cluster at the magnetospheric cusps. Space Sci. Rev., 118(1-4), 321-366. https://doi.org/10.1007/s11214-005-3835-0

Chapman, S., and Ferraro, V. C. A. (1930). A new theory of magnetic storms. Nature, 126(3169), 129-130. https://doi.org/10.1038/126129a0

Chen, J. S., and Fritz, T. A. (1998). Correlation of cusp MeV helium with turbulent ULF power spectra and its implications. Geophys. Res. Lett., 25(22), 4113-4116. https://doi.org/10.1029/1998GL900122

Chen, J. S., Fritz, T. A., and Sheldon, R. B. (2005). Comparison of energetic ions in cusp and outer radiation belt. J. Geophys. Res., 110(A12), A12219. https://doi.org/10.1029/2004JA010718

Delcourt, D. C., and Sauvaud, J. A. (1999). Populating of the cusp and boundary layers by energetic (hundreds of keV) equatorial particles. J. Geophys. Res., 104(A10), 22635-22648. https://doi.org/10.1029/1999JA900251

Duan, S. P., Liu, Z. X., Cao, J. B., Shi, J. K., Lu, L., Li, Z. Y., Zong, Q.-G., Reme, H., Cornilleau-Wehrlin, N., Balogh, A., Andre, M. (2006). Analysis of the interaction between low-frequency waves and ions in the high-altitude cusp region observed by satellite Cluster. Chinese Physics Letters, 23(5), 1351-1354. https://doi.org/10.1088/0256-307X/23/5/079

Dungey, J. W. (1961). Interplanetary magnetic field and the auroral zones. Phys. Rev. Lett., 6(2), 47-48. https://doi.org/10.1103/PhysRevLett.6.47

Dunlop, M. W., Lavraud, B., Cargill, P., Taylor, M. G. G. T., Balogh, A., Réme, H., Decreau, P., Glassmeier, K.-H., Elphic, R. C., ... Marchaudon, A. (2005). Cluster observations of the cusp: magnetic structure and dynamics. In T. A. Fritz, et al. (Eds.), The Magnetospheric Cusps: Structure and Dynamics (pp. 5-55). Dordrecht: Springer. https://doi.org/10.1007/1-4020-3605-1_2

Escoubet, C., and Bosqued, J. M. (1989). The influence of IMF-Bz and/or AE on the polar cusp: an overview of observations from the AUREOL-3 satellite. Planet. Space Sci., 37(5), 609-626. https://doi.org/10.1016/00320633(89)90100-1

Grigoriev, A. Y., Fedorov, A. O., Budnik, E. Y., and Nikolaeva, N. S. (1999). Magnetospheric magnetic field in the outer cusp region: comparison of measurements obtained from the INTERBALL-1 satellite and from the T96 model. Cosmic Res., 37(6), 594-599.

Haerendel, G., Paschmann, G., Sckopke, N., Rosenbauer, H., and Hedgecock, P. C. (1978). The frontside boundary layer of the magnetosphere and the problem of reconnection. J. Geophys. Res., 83(A7), 3195-3216. https://doi.org/10.1029/JA083iA07p03195

Haerendel, G., and Paschmann, G. (1982). Interaction of the solar wind with the dayside magnetosphere. In A. Nishida (Ed.), Magnetospheric Plasma Physics (pp. 81-122). Dordrecht: D. Reidel Publishing.

Heikkila, W. J., and Winningham, J. D. (1971). Penetration of magnetosheath plasma to low altitudes through the dayside magnetospheric cusps. J. Geophys. Res., 76(4), 883-891. https://doi.org/10.1029/JA076i004p00883

Heikkila, W. J. (1985). Definition of the cusp. In J. A. Holtet, et al. (Eds.), The Polar Cusp (pp. 387-395). Dordrecht: Springer. https://doi.org/10.1007/978-94009-5295-9_28

Johnsen, M. G., and Lorentzen, D. A. (2012). A statistical analysis of the optical dayside open/closed field line boundary. J. Geophys. Res., 117(A2), A02218. https://doi.org/10.1029/2011JA016984

Lavraud, B., Dunlop, M. W., Phan, T. D., Rème, H., Bosqued, J. M., Dandouras, I., Sauvaud, J. A., Lundin, R., Taylor, M. G. G. T., ... Balogh, A. (2002). Cluster observations of the exterior cusp and its surrounding boundaries under northward IMF. Geophys. Res. Lett., 29(20), 1995.

https://doi.org/10.1029/2002GL015464

Lavraud, B., Phan, T. D., Dunlop, M. W., Taylor, M. G. G. G. T., Cargill, P. J., Bosqued, J. M., Dandouras, I., Rème, H., Sauvaud. J. A., ... Fazakerley, A. (2004). The exterior cusp and its boundary with the magnetosheath: Cluster multi-event analysis. Ann. Geophys., 22(8), 3039-3054.

https://doi.org/10.5194/angeo-22-3039-2004

Lavraud, B., Fedorov, A., Budnik, E., Thomsen, M. F., Grigoriev, A., Cargill, P. J., Dunlop, M. W., Rème, H., Dandouras, l., and Balogh, A. (2005). High-altitude cusp flow dependence on IMF orientation: a 3-year Cluster statistical study. J. Geophys. Res., 110(A2), A02209. https://doi.org/10.1029/2004JA010804

Le, G., Blanco-Cano, X., Russell, C. T., Zhou, X. W., Mozer, F., Trattner, K. J., Fuselier, S. A., and Anderson, B. J. (2001). Electromagnetic ion cyclotron waves in the high-altitude cusp: Polar observations. J. Geophys. Res., 106(A9), 19067-19079. https://doi.org/10.1029/2000JA900163

Liu, W. L., Tu, W. C., Li, X. L., Sarris, T., Khotyaintsev, Y., Fu, H. S., Zhang, H., and Shi, Q. Q. (2016). On the calculation of electric diffusion coefficient of radiation belt electrons with in situ electric field measurements by THEMIS. Geophys. Res. Lett., 43(3), 1023-1030. https://doi.org/10.1002/2015GL067398

Lockwood, M., and Smith, M. F. (1992). The variation of reconnection rate at the dayside magnetopause and cusp ion precipitation. J. Geophys. Res., 97(A10), 14841-14847. https://doi.org/10.1029/92JA01261

Lockwood, M., and Smith, M. F. (1994). Low and middle altitude cusp particle signatures for general magnetopause reconnection rate variations: 1. Theory. J. Geophys. Res., 99(A5), 8531-8553. https://doi.org/10.1029/93JA03399

Měrka, J., Šafránková, J., and Němeček, Z. (2002). Cusp-like plasma in high altitudes: a statistical study of the width and location of the cusp from Magion-4. Ann. Geophys., 20(3), 311-320. https://doi.org/10.5194/angeo-20311-2002

Newell, P. T., and Meng, C.-I. (1987). Cusp width and $B_{z}$ : Observations and a conceptual model. J. Geophys. Res., 92(A12), 13673-13678. https://doi.org/10.1029/ja092ia12p13673

Newell, P. T., and Meng, C.-I. (1989). Dipole tilt angle effects on the latitude of the cusp and cleft/low-latitude boundary layer. J. Geophys. Res., 94(A6), 6949-6953. https://doi.org/10.1029/ja094ia06p06949

Newell, P. T., Meng, C.-I., Sibeck, D. G., and Lepping, R. (1989). Some low-altitude cusp dependencies on the interplanetary magnetic field. J. Geophys. Res., 94(A7), 8921-8927. https://doi.org/10.1029/JA094iA07p08921

Newell, P. T., and Meng, C.-I. (1994). lonospheric projections of magnetospheric regions under low and high solar wind pressure conditions. J. Geophys. Res., 99(A1), 273-286. https://doi.org/10.1029/93ja02273

Niehof, J. T., Fritz, T. A., Friedel, R. H. W., and Chen, J. S. (2010). Size and location of cusp diamagnetic cavities observed by Polar. J. Geophys. Res., 115(A7), A07201. https://doi.org/10.1029/2009JA014827

Nykyri, K., Cargill, P. J., Lucek, E., Horbury, T., Lavraud, B., Balogh, A., Dunlop, M. W., Bogdanova, Y., Fazakerley, A., ... Rème, H. (2004). Cluster observations of magnetic field fluctuations in the high-altitude cusp. Ann. Geophys., 22(7), 2413-2429. https://doi.org/10.5194/angeo-22-2413-2004

Nykyri, K., Grison, B., Cargill, P. J., Lavraud, B., Lucek, E., Dandouras, I., Balogh, A., Cornilleau-Wehrlin, N., and Rème, H. (2006). Origin of the turbulent spectra in the high-altitude cusp: cluster spacecraft observations. Ann. Geophys., 24(3), 1057-1075. https://doi.org/10.5194/angeo-24-1057-2006

Nykyri, K., Otto, A., Adamson, E., Dougal, E., and Mumme, J. (2011). Cluster observations of a cusp diamagnetic cavity: Structure, size, and dynamics. J. Geophys. Res., 116(A3), A03228. https://doi.org/10.1029/2010JA015897

Palmroth, M., Laakso, H., and Pulkkinen, T. I. (2001). Location of high-altitude cusp during steady solar wind conditions. J. Geophys. Res., 106(A10), 21109-21122. https://doi.org/10.1029/2001JA900073

Paschmann, G., Haerendel, G., Sckopke, N., Rosenbauer, H., and Hedgecock, P. C. (1976). Plasma and magnetic field characteristics of the distant polar cusp near local noon: the entry layer. J. Geophys. Res., 81(16), 2883-2899. https://doi.org/10.1029/ja081i016p02883

Peng, F. Z., Fu, H. S., Cao, J. B., Graham, D. B., Chen, Z. Z., Cao, D., Xu, Y., Huang, S. Y., Wang, T. Y., ... Burch, J. L. (2017). Quadrupolar pattern of the asymmetric guide-field reconnection. J. Geophys. Res., 122(6), 6349-6356. https://doi.org/10.1002/2016JA023666 
Pitout, F., Escoubet, C. P., Bogdanova, Y. V., Georgescu, E., Fazakerley, A. N., and Rème, H. (2006). Response of the mid-altitude cusp to rapid rotations of the IMF. Geophys. Res. Lett., 33(11), L11107. https://doi.org/10.1029/2005GL025460

Prölss, G. W. (2006). Electron temperature enhancement beneath the magnetospheric cusp. J. Geophys. Res., 111(A7), A07304. https://doi.org/10.1029/2006JA011618

Rème, H., Aoustin, C., Bosqued, J. M., Dandouras, I., Lavraud, B., Sauvaud, J. A., Barthe, A., Bouyssou, J., Camus, T., ... Sonnerup, B. (2001). First multispacecraft ion measurements in and near the Earth's magnetosphere with the identical Cluster ion spectrometry (CIS) experiment. Ann. Geophys., 19(10-12), 1303-1354. https://doi.org/10.5194/angeo-19-1303-2001

Rosenbauer, H., Grünwaldt, H., Montgomery, M. D., Paschmann, G., and Sckopke, N. (1975). Heos 2 plasma observations in the distant polar magnetosphere: the plasma mantle. J. Geophys. Res., 80(19), 2723-2737. https://doi.org/10.1029/JA080i019p02723

Russell, C. T., and Elphic, R. C. (1979). ISEE observations of flux transfer events at the dayside magnetopause. Geophys. Res. Lett., 6(1), 33-36. https://doi.org/10.1029/GL006i001p00033

Russell, C. T., Fedder, J. A., Slinker, S. P., Zhou, X. W., Le, G., Luhmann, J. G., Fenrich, F. R., Chandler, M. O., Moore, T. E., and Fuselier, S. A. (1998). Entry of the POLAR spacecraft into the polar cusp under northward IMF conditions. Geophys. Res. Lett., 25(15), 3015-3018. https://doi.org/10.1029/98GL00355

Savin, S., Büchner, J., Consolini, G., Nikutowski, B., Zelenyi, L., Amata, E., Auster, H. U., Blecki, J., Dubinin, E., ...Yermolaev, Y. (2002). On the properties of turbulent boundary layer over polar cusps. Nonlinear Processes Geophys., 9(5-6), 443-451. https://doi.org/10.5194/npg-9-443-2002

Savin, S., Zelenyi, L., Romanov, S., Sandahl, I., Pickett, J., Amata, E., Avanov, L., Blecki, J., Budnik, E., ... Yermolaev, Y. (2004). Magnetosheath-cusp interface. Ann. Geophys., 22(1), 183-212. https://doi.org/10.5194/angeo-22-183-2004

Savin, S. P., Romanov, S. A., Fedorov, A. O., Zelenyi, L., Klimov, S. I., Yermolaev, Y. I., Budnik, E. Y., Nikolaeva, N. S., Russell, C. T., ... Reiff, P. H. (1998). The cusp/magnetosheath interface on May 29, 1996: interball-1 and Polar observations. Geophys. Res. Lett., 25(15), 2963-2966. https://doi.org/10.1029/98GL01402

Sckopke, N., Paschmann, G., Rosenbauer, H., and Fairfield, D. H. (1976). Influence of the interplanetary magnetic field on the occurrence and thickness of the plasma mantle. J. Geophys. Res., 81(16), 2687-2691. https://doi.org/10.1029/JA081i016p02687

Sckopke, N., and Paschmann, G. (1978). The plasma mantle. A survey of magnetotail boundary layer observations. J. Atmos. Terr. Phys., 40(3), 261-278. https://doi.org/10.1016/0021-9169(78)90044-2

Sheldon, R. B., Spence, H. E., Sullivan, J. D., Fritz, T. A., and Chen, J. S. (1998). The discovery of trapped energetic electrons in the outer cusp. Geophys. Res. Lett., 25(11), 1825-1828. https://doi.org/10.1029/98gl01399

Shen, C., Dunlop, M., Ma, Y. H., Chen, Z. Q., Yan, G. Q., Liu, Z. X., Bogdanova, Y. V., Sibeck, D. G., Carr, C. M., ... Lucek, E. (2011). The magnetic configuration of the high-latitude cusp and dayside magnetopause under strong magnetic shears. J. Geophys. Res., 116(A9), A09228. https://doi.org/10.1029/2011JA016501

Shi, Q. Q., Zong, Q.-G., Zhang, H., Pu, Z. Y., Fu, S. Y., Xie, L., Wang, Y. F., Chen, Y., Li, L., ... Lucek, E. (2009a). Cluster observations of the entry layer equatorward of the cusp under northward interplanetary magnetic field. J. Geophys. Res., 114(A12), A12219. https://doi.org/10.1029/2009JA014475

Shi, Q. Q., Pu, Z. Y., Soucek, J., Zong, Q.-G., Fu, S. Y., Xie, L., Chen, Y., Zhang, H., Li, L., ... Rème, H. (2009b). Spatial structures of magnetic depression in the
Earth's high-altitude cusp: cluster multipoint observations. J. Geophys. Res., 114(A10), A10202. https://doi.org/10.1029/2009JA014283

Tsyganenko, N. A., and Stern, D. P. (1996). Modeling the global magnetic field of the large-scale Birkeland current systems. J. Geophys. Res., 101(A12), 27187-27198. https://doi.org/10.1029/96JA02735

Walsh, B. M., and Fritz, T. A. (2011). Cluster energetic electron survey of the high-altitude cusp and adjacent regions. J. Geophys. Res., 116(A12), A12212. https://doi.org/10.1029/2011JA016828

Wang, T. Y., Cao, J. B., Fu, H. S., Liu, W. L., and Dunlop, M. (2014). Turbulence in the Earth's cusp region: The $k$-filtering analysis. J. Geophys. Res., 119(12), 9527-9542. https://doi.org/10.1002/2014JA019997

Xiao, C., Liu, W. L., Shen, C., Zhang, H., and Rong, Z. J. (2018). Study on the curvature and gradient of the magnetic field in Earth's cusp region based on the magnetic curvature analysis method. J. Geophys. Res., 123(5), 3794-3805. https://doi.org/10.1029/2017JA025028

Yu, Y. Q., and Ridley, A. J. (2009). Response of the magnetosphere-ionosphere system to a sudden southward turning of interplanetary magnetic field. J. Geophys. Res., 114(A3), A03216. https://doi.org/10.1029/2008JA013292

Yu, Y. Q., and Ridley, A. J. (2013). Exploring the influence of ionospheric $\mathrm{O}^{+}$ outflow on magnetospheric dynamics: Dependence on the source location. J. Geophys. Res., 118(4), 1711-1722. https://doi.org/10.1029/2012JA018411

Zhang, H., Fritz, T. A., Zong, Q.-G., and Daly, P. W. (2005). Stagnant exterior cusp region as viewed by energetic electrons and ions: $A$ statistical study using Cluster Research with Adaptive Particle Imaging Detectors (RAPID) data. J. Geophys. Res., 110(A5), A05211. https://doi.org/10.1029/2004JA010562

Zhang, H., Fritz, T. A., Zong, Q.-G., and Daly, P. W. (2006). The high latitude boundaries under extreme solar wind conditions: a cluster perspective. In W. H. Ip, et al. (Eds.), Advances in Geosciences (pp. 163-172). Hackensack: World Scientific. https://doi.org/10.1142/9789812707185_0013

Zhang, H., Dunlop, M. W., Zong, Q.-G., Fritz, T. A., Balogh, A., and Wang, Y. (2007). Geometry of the high-latitude magnetopause as observed by Cluster. J. Geophys. Res., 112(A2), A02204. https://doi.org/10.1029/2006JA011774

Zhou, X. W., Russell, C. T., Le, G., Fuselier, S. A., and Scudder, J. D. (1999). The polar cusp location and its dependence on dipole tilt. Geophys. Res. Lett., 26(3), 429-432. https://doi.org/10.1029/1998GL900312

Zhou, X. W., Russell, C. T., Le, G., Fuselier, S. A., and Scudder, J. D. (2000). Solar wind control of the polar cusp at high altitude. J. Geophys. Res., 105(A1), 245-251. https://doi.org/10.1029/1999ja900412

Zhou, X.-Z., Fritz, T. A., Zong, Q.-G., Pu, Z. Y., Hao, Y.-Q., and Cao, J.-B. (2006). The cusp: a window for particle exchange between the radiation belt and the solar wind. Ann. Geophys., 24(11), 3131-3137. https://doi.org/10.5194/angeo-24-3131-2006

Zong, Q.-G., Fritz, T. A., Zhang, H., Korth, A., Daly, P. W., Dunlop, M. W., Glassmeier, K.-H., Rème, H., and Balogh, A. (2004). Triple cusps observed by Cluster-Temporal or spatial effect?. Geophys. Res. Lett., 31(9), L09810. https://doi.org/10.1029/2003GL019128

Zong, Q.-G., Fritz, T. A., Spence, H., Zhang, H., Huang, Z. Y., Pu, Z. Y., Glassmeier, K.-H., Korth, A., Daly, P. W., ... Rème, H. (2005). Plasmoid in the high latitude boundary/cusp region observed by Cluster. Geophys. Res. Lett., 32(1), L01101. https://doi.org/10.1029/2004GL020960

Zong, Q.-G., Fritz, T. A., Zhang, H., Fu, S. Y., Zhou, X. Z., Goldstein, M. L., Daly, P. W., Rème, H., Balogh, A., and Fazakerley, A. N. (2006). The magnetospheric cusp: structure and dynamics. In W. H. Ip, et al. (Eds.), Advances in Geosciences (pp. 173-189). Hackensack: World Scientific. https://doi.org/10.1142/9789812707185_0014 